This item was submitted to Loughborough's Research Repository by the author.

Items in Figshare are protected by copyright, with all rights reserved, unless otherwise indicated.

\title{
Flexible reduced graphene oxide/polyacrylonitrile dielectric nanocomposite films for high-temperature electronics applications
}

\section{PLEASE CITE THE PUBLISHED VERSION}

https://doi.org/10.1021/acsanm.0c01328

\section{PUBLISHER}

American Chemical Society (ACS)

\section{VERSION}

AM (Accepted Manuscript)

\section{PUBLISHER STATEMENT}

This document is the Accepted Manuscript version of a Published Work that appeared in final form in ACS Applied Nano Materials, copyright $@$ American Chemical Society after peer review and technical editing by the publisher. To access the final edited and published work see https://pubs.acs.org/doi/10.1021/acsanm.0c01328.

\section{LICENCE}

CC BY-NC-ND 4.0

\section{REPOSITORY RECORD}

Su, Yaotian, Wenqing Zhang, Jinle Lan, Gang Sui, Hongtao Zhang, and Xiaoping Yang. 2020. "Flexible Reduced Graphene Oxide/polyacrylonitrile Dielectric Nanocomposite Films for High-temperature Electronics Applications". Loughborough University. https://hdl.handle.net/2134/12619670.v1. 


\title{
Flexible Reduced Graphene Oxide/Polyacrylonitrile Dielectric
} Nanocomposite Films for High-Temperature Electronics Applications Yaotian Su, ${ }^{\text {a }}$ Wenqing Zhang, ${ }^{\text {a Jinle Lan, }}{ }^{\mathrm{a}}$ Gang Sui, ${ }^{\mathrm{a}}$ Hongtao Zhang, ${ }^{\mathrm{b}}$ Xiaoping Yang ${ }^{\mathrm{a}}$

${ }^{\text {a }}$ State Key Laboratory of Organic-Inorganic Composites, Beijing University of Chemical Technology, Beijing100029, China

${ }^{\mathrm{b}}$ Department of Materials, Loughborough University, Leicestershire, UK

*Corresponding authors:

* Gang Sui. Tel: +86-15301140646. Email: suigang@mail.buct.edu.cn

*Xiaoping Yang. Tel: +86-13601115033. Email: yangxp@mail.buct.edu.cn

\begin{abstract}
Polymer dielectrics possess excellent flexibility compared with inorganic ceramic materials. However, the relatively low dielectric constant and working temperature significantly constrains their widespread application. Here, we report a low-cost facile strategy to develop flexible polymer-based composite films with high dielectric constant over a broad temperature. Polyacrylonitrile (PAN) nanofiber mats containing graphene oxide (GO) with core-shell microstructure were firstly prepared via coaxial electrospinning and then hot-pressed into dense composite films. It was revealed that hot-pressing assisted by a stretching force under appropriate temperature and pressure can generate local conformational changes of PAN, leading to the formation of an electroactive phase with increased dielectric constant. Meanwhile, the GO transformed into reduced graphene oxide (rGO) under heat reduction, serving as conductive nanofillers to further promote the increase of dielectric constant. Consequently, the optimized rGO/PAN composites displayed thermally stable dielectric properties with a high dielectric constant $\left(\varepsilon^{\prime}=23,80^{\circ} \mathrm{C} ; \varepsilon^{\prime}=40,150^{\circ} \mathrm{C}\right)$ and low loss $(\tan \delta=0.13$,
\end{abstract}


$80^{\circ} \mathrm{C} ; \tan \delta=0.55,150^{\circ} \mathrm{C}$ ) over a broad temperature range. This work offers an efficient method for the synthesis of flexible composite dielectric films that hold great potential in high-temperature electronic applications.

Keywords: Dielectrics; Polyacrylonitrile; Reduced graphene oxide; Coaxial electrospinning; High-temperature performance

\section{Introduction}

Dielectric materials, which store energy electrostatically, have been finding broad applications in advanced electronic industries such as hybrid electric vehicles, electric grids, aircraft, and pulse power systems [1-3]. Compared with inorganic ceramics, polymer-based dielectrics possess intrinsic advantages including lightweight, facile processability, flexibility, and high breakdown strength [4-5]. However, the modern power industry poses new challenges for the traditional polymer dielectrics because their relatively low dielectric constant and working temperature fail to meet the rising demand in harsh conditions. For example, the commercially used dielectric polymers, biaxially oriented polypropylene (BOPP), cannot be applied at high temperatures over $80^{\circ} \mathrm{C}$ because of the rising dielectric loss (tan $\left.\delta\right)$ and mechanical degradations attributed to chain segment movement above the glass transition temperature $\left(\mathrm{T}_{\mathrm{g}}\right)$. Furthermore, the low dielectric constant $\left(\varepsilon^{\prime}=2\right)$ of BOPP limited their energy storage capability [6-10].

Several strategies have been proposed in the past to raise the dielectric constant of polymer-based dielectrics and improve their stability within a high-temperature range. Some researchers have been exploring the preparation and modification of polymer-based dielectrics with a high glass transition temperature. For example, Li et al. [11] synthesized 
crosslinked divinyltetramethyldisiloxane-bis(benzocyclobutene) (BCB) in the presence of boron nitride nanosheets ( $\mathrm{cBCB} / \mathrm{BNNS}$ ). The composites showed dielectric stability over a wide temperature range $\left(30-150^{\circ} \mathrm{C}\right)$ and the corresponding dielectric constant $\left(\varepsilon^{\prime}\right)$ was 3.1 at 1kHz. Zhang et al. [12] fabricated poly (arylene ether urea) (PEEU) composites with 20-nm-sized alumina as nanofillers. The composite films exhibited a $\varepsilon^{\prime}$ of 7.4 , increased from 4.7 of the base PEEU films, and a broad temperature range stability to $150^{\circ} \mathrm{C}$. According to the studies illustrated above, we can see that synthesizing these polymers was costly and time-consuming, which was not suitable for industrial production. Besides, the recommendable dielectric performance of these composites was mainly the intrinsic high breakdown strength of the polymer matrix when applied in the high voltage filed. But the energy-storage performance of these polymer materials would be severely restricted because of their low dielectric constant $\left(\varepsilon^{\prime}<10\right)$.

Polyacrylonitrile (PAN) is a well-known low-cost polymer that has been widely used as a principal precursor to supply $90 \%$ of commercial carbon fibers worldwide [13]. PAN not only contains a high level of permanent dipoles with strong interchain interactions between nitrile groups but also possesses a stable amorphous phase in $90-180^{\circ} \mathrm{C}$ which makes it a potential candidate as high-temperature dielectric materials [14]. However, despite the dipole moment of -CN-C groups are 3.5 Debye, which is larger than that of C-F (2.1 Debye) in polyvinylidene fluoride (PVDF) matrix, the dielectric constant of PAN $\left(\varepsilon^{\prime}=3.1\right)$ is much lower than that of PVDF $\left(\varepsilon^{\prime}=6-8\right)$. This phenomenon has disturbed the researchers for a long time until recently Wang et al. [15] discovered that the piezoelectricity of PAN was largely dependent on the proportion of zig-zag conformation in PAN and by controlling the heat 
treatment conditions, the piezoelectricity can be well regulated. However, this research only showed us the piezoelectric properties of the porous electrospun nanofiber mats, and for application in the energy storage field, the dielectric properties of the dense nonporous films need to be further investigated.

In this work, we successfully prepared a flexible reduced graphene oxide (rGO) /PAN dielectric composite film combining electrospinning and heat treatment methods. The oriented core-shell structured graphene oxide (GO) filled PAN nanofiber mats with different PAN shell thickness were firstly fabricated through coaxial electrospinning procedures. Then a well-designed hot-pressing treatment was conducted on the electrospun mat under the stretching force. The flexible dense films can be prepared under this procedure, meanwhile, the GO was reduced to rGO acting as conductive fillers to form microcapacitors in the PAN matrix. By controlling the electrospinning parameters and heat treatment process, a series of composite films with varying PAN conformational microstructure can be obtained. The influence of the PAN conformation and shell thickness of the nanofibers on the dielectric performance was systematically investigated. The results showed that the optimized composite films containing $20 \mathrm{wt} \% \mathrm{rGO}$ with PAN nanofibers shell thickness $\sim 10 \mathrm{~nm}$ can exhibit a high dielectric constant $\left(\varepsilon^{\prime}=23,80^{\circ} \mathrm{C} ; 40,150^{\circ} \mathrm{C}\right)$ and low loss $\left(\tan \delta=0.13,80^{\circ} \mathrm{C}\right.$; $0.55,150^{\circ} \mathrm{C}$ ) over a broad temperature range, which made it possible for the electronics applications in the extreme environment.

\section{Experimental}

\subsection{Materials}

Polyacrylonitrile (PAN, $\mathrm{Mw}=100000)$ was purchased from Spectrum Chemical 
Manufacturing Co., USA. Graphene oxide (GO, average sheet size was $\sim 2 \mu \mathrm{m}$ ) was produced by Xianfeng Nanomaterials Tech. Co., China. N,N-dimethylformamide (DMF) ( $\geq 99 \%$ ) was obtained from Beijing Chemical Factory, China. All materials were used as received.

\subsection{Preparation of PAN films}

The flexible dense PAN films were prepared by electrospinning combined with hot-pressing and stretching methods. PAN solution $(13 \% \mathrm{w} / \mathrm{v})$ was firstly prepared by dissolving PAN powders into DMF and then poured into an injection syringe to conduct the electrostatic spinning process. The device parameters including applied voltage and flow rate were carefully regulated until perfect Taylor Cone can be observed at the needle tip. The rotate speed of the roller drum collector maintained $1300 \mathrm{r} / \mathrm{min}$ to facilitate the resultant nanofiber mat with good orientation. The as-prepared nanofiber mat was finally hot-pressed for $6 \mathrm{~h}$ under different temperatures $\left(150^{\circ} \mathrm{C}, 180^{\circ} \mathrm{C}, 200^{\circ} \mathrm{C}\right)$ with a stretching force $(15 \mathrm{~N})$ in the nanofiber-oriented directions. Finally, a series of flexible dense PAN films were successfully fabricated as shown in Fig S2.

\subsection{Preparation of GO/PAN core-shell structural nanofiber mats}

The GO/PAN core-shell structural nanofiber mats were fabricated by coaxial electrospinning methods. PAN solution $(13 \% \mathrm{w} / \mathrm{v})$ was firstly prepared by dissolving PAN powders into DMF and heated at $65{ }^{\circ} \mathrm{C}$ for $3 \mathrm{~h}$. A certain amount of GO was firstly dispersed in DMF under the ultrasonic condition for $2 \mathrm{~h}$ and then mixed with PAN solution for another $2 \mathrm{~h}$ before electro-spinning. The coaxial electrospinning procedures were a modification of a traditional single spinneret electrospinning setup. The single spinneret was replaced by two coaxial 
capillaries in which two channels were connected to two reservoirs. The coaxial configuration of nozzles can provide different pathways for inner and outer solutions [16]. In this study, the inner path was filled with a certain concentration of GO/PAN solution while the outer path was available to pure PAN solution. A high voltage DC power was applied to generate an electric field. During electrospinning, the applied voltage was from 15 to $20 \mathrm{kV}$ based on the concentration of solution within inner and outer channels. The determination of the flow rate of the solution from the inner and outer paths also depended on the change of solution composition, and a typical flow rate was $0.5 \mathrm{~mL} / \mathrm{h}$ and $0.8 \mathrm{~mL} / \mathrm{h}$, respectively. The distance was usually $15 \mathrm{~cm}$ from needle to roller drum collector. The PAN shell thickness and fiber orientation of the nanofiber mats were controlled by electrospinning time and rotate speed of collector. The mechanism is shown in Fig. 1(a).

\subsection{Preparation of rGO/PAN composite films}

To prepare flexible dense rGO/PAN composite films, a comparable technique referring to section 2.2 was employed. As illustrated in Fig. 1(b), the electrospun nanofiber mat was firstly cold pressed under $30 \mathrm{MPa}$ for $2 \mathrm{~min}$ at room temperature. In this case, the interspace between nanofibers could be intensively squeezed because of the synergistic effect from both ambient pressure and the interactions among polar groups on the PAN chains [17-18]. The cold-compressed film was then hot pressed at specified temperatures $\left(180^{\circ} \mathrm{C}, 200^{\circ} \mathrm{C}\right)$ under $5 \mathrm{MPa}$ for $6 \mathrm{~h}$ with the assistance of a stretching force in one direction. It should be noted that in this step, low pressure was firstly exerted to facilitate the stretching of the nanofiber mat, and then the pressure was gradually building up to $5 \mathrm{MPa}$. Consequently, a series of rGO/PAN composite films with different molecular chain structures was obtained which was coded as 
$\mathrm{x}-\mathrm{y}$ shell $\mathrm{rGO} / \mathrm{PAN}$, where $\mathrm{x}$ represented the heat treatment temperature and $\mathrm{y}$ was the thickness of PAN nanofiber shell before hot-pressed.

\subsection{Characterization}

Attenuated total reflection Fourier transform infrared spectra (ATR-FTIR, Bruker Tensor 27, Bruker Daltonics, Germany) was used to characterize the functional groups of GO and PAN composites. The core-shell morphologies of the electrospun nanofibers were identified by transmission electron microscopy (TEM, Tecnai, model G220, USA); in this experiment, the samples were obtained by placing a copper grid on the roller drum collector when the electro-spinning proceeded. The crystalline structure of the PAN composite films was analyzed by X-ray diffraction (XRD, XRD-7000, Shimadzu, Japan) with a pass energy of 29.35eV and an $\mathrm{Mg}$ Ka line excitation source. The microstructure of the rGO/PAN nanofiber mat and fracture surface of the composite film was characterized using an inspect scanning electron microscope instrument (SEM, JSM-7401F, JEOL, Japan) with an acceleration voltage of $5 \mathrm{kV}$. Raman spectra was performed (a Senterra R200-L, Bruker Optics, Germany) to characterize the GO before and after heat treatment. The dielectric and electrical properties of samples were measured by a broadband impedance analyzer (Novocontrol Technologies, Germany). The temperature was controlled from 50 to $150^{\circ} \mathrm{C}$ by $\mathrm{TC} 202$ temperature controller which was provided by Hisuntest technique corporation. 


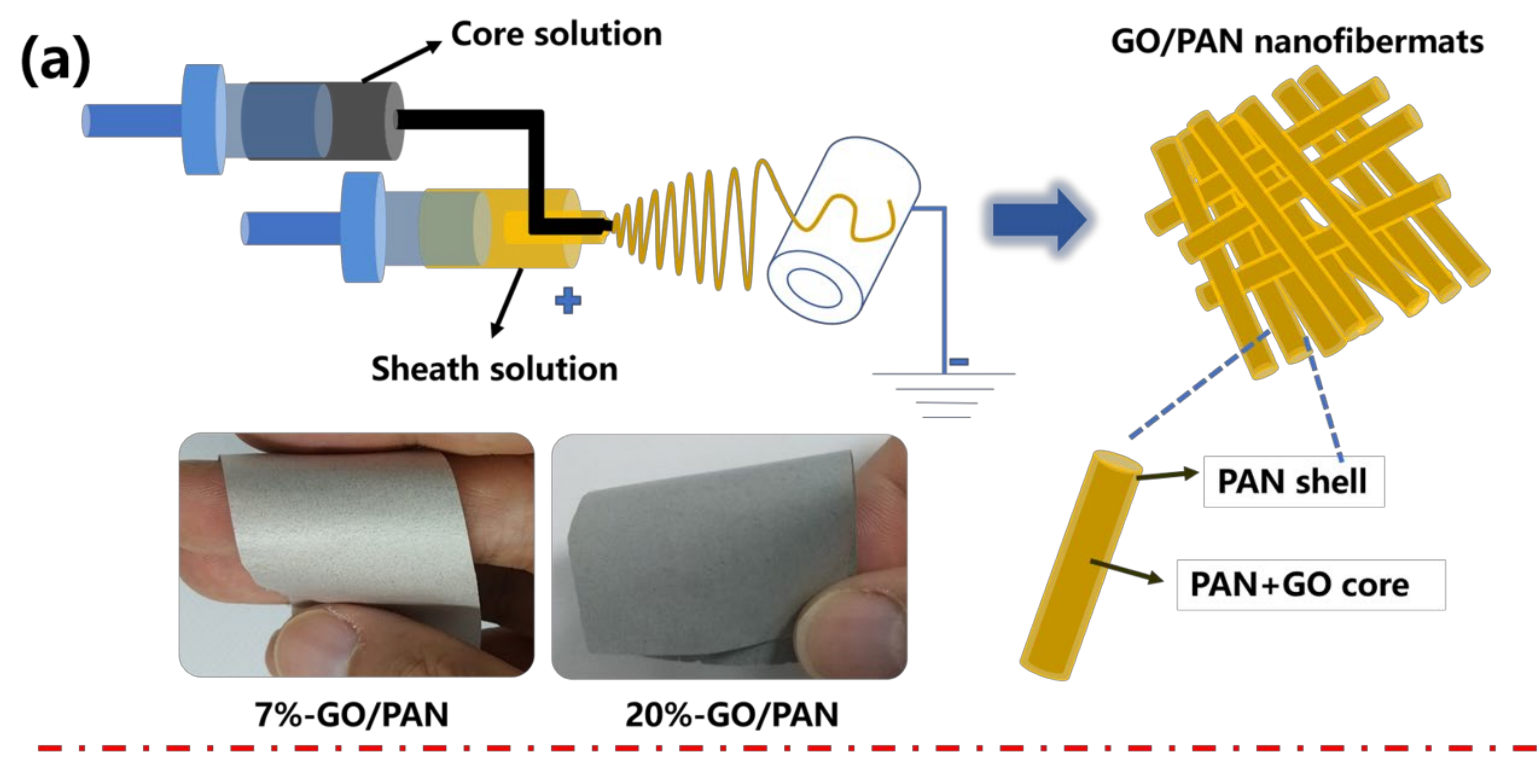

(b)

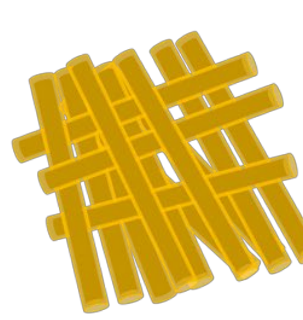

fibrous film

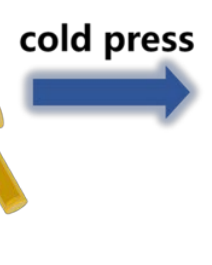

compressed film

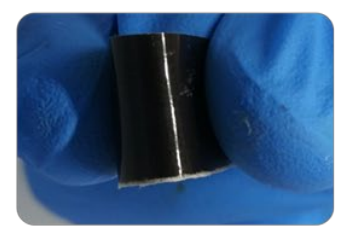

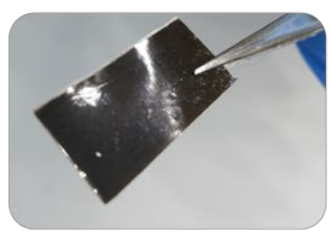

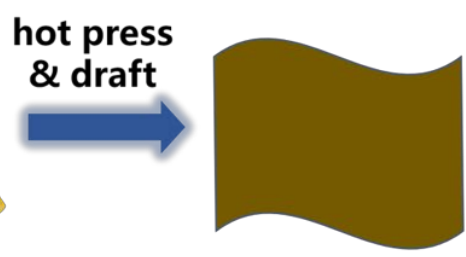

dense film

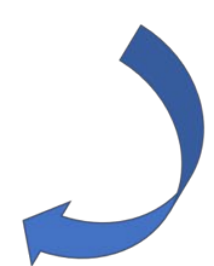

Fig. 1 (a) Mechanism of preparing GO/PAN core-shell structural nanofiber mats by coaxial electrospinning (b) procedures of fabricating flexible rGO/PAN composite film.

\section{Results and discussion}

\subsection{Molecular structural transformation of PAN}

It has been demonstrated by Wang et al. [15] that PAN can generate conformational changes under different processing conditions, thereby influencing the piezoelectric properties of the prepared nanofiber mats. Fig S1 shows the two typical conformations of PAN molecules, i.e. planar zigzag (also called "saw-tooth") and $3^{1}$-helical. The zigzag conformation had an all-trans (TTTT) structure with a dipole moment of 3.5 Debye, constituting the electroactive phase which was beneficial for the enhancement of dielectric properties [19]. However, the 
industrial production of PAN was based on the urea clathrate polymerization method [20], by which the resulting product mainly consisted of the $3^{1}$-helical conformation structures. This structure was not as ordered as that of zigzag because the $-\mathrm{CN}$ groups in the $3^{1}$-helical conformations would be mutually excluded from each other, leading to the transition towards disordered structures. Therefore, the dielectric constant of the material was not as high as expected. To improve the dielectric performance of the material, we utilized a high-speed electrospinning method combined with the hot-pressing and stretching process to prepare the PAN with a high proportion of zigzag conformation.

Fig. 2(e) shows the FTIR spectra of PAN films after treated by the hot-pressing combined with stretching procedures. The absorption band around $2224 \mathrm{~cm}^{-1}$ can be observed in the pristine PAN samples which verified the existence of $-\mathrm{CN}$ groups in the PAN structure [21-22]. After heat-treatment, the PAN samples exhibited the strengthened absorption peaks at $1673 \mathrm{~cm}^{-1}$ representing the increase of $-\mathrm{C}=\mathrm{O}$ groups which were attributed to the moderate oxidation of $-\mathrm{CH}$ groups when exposed to air atmosphere at high temperatures [23-25]. No other new characteristic peaks appeared in the heat-treated PAN samples compared with the pristine one, which demonstrated there was no cyclization and decomposition reactions occurred in the temperature range from $150^{\circ} \mathrm{C}$ to $200^{\circ} \mathrm{C}$ although the samples treated by $200^{\circ} \mathrm{C}$ showed slight yellow colors (see Fig S2). Fig. 2(a)-(d) presents the local magnified FTIR spectra of PAN in the wavenumber range from $1200-1300 \mathrm{~cm}^{-1}$ after heat-treated with different temperatures. It has been demonstrated by many researchers that the vibration bands at around $1250 \mathrm{~cm}^{-1}$ and $1230 \mathrm{~cm}^{-1}$ corresponded to zigzag conformation and $3^{1}$-helical conformation, respectively [21]. The content of the zigzag conformation $(\Phi)$ can be estimated using the Eq. 
(1)

$$
\Phi=\mathrm{S}_{1250} /\left(\mathrm{S}_{1250}+\mathrm{S}_{1230}\right)
$$

where $S_{1230}$ and $S_{1250}$ are the peak area at $1230 \mathrm{~cm}^{-1}$ and $1250 \mathrm{~cm}^{-1}$, respectively.

By simulating the peaks and calculating the peak area, the PAN films heat-treated under $200^{\circ} \mathrm{C}$ showed an $\Phi$ of $75 \%$, which was higher than that of the pristine PAN $(\Phi=45 \%)$. It provided an evident proof that the hot-pressing and stretching treatment at a higher temperature facilitated the structural conversion in PAN from $3^{1}$-helical to zigzag conformation. To give a further demonstration, XRD patterns of the samples under different treatment temperatures are shown in Fig. 2(f). An intense sharp reflection around $2 \theta=17^{\circ}$ corresponding to a lateral repeat distance $\sim 5.4 \AA$ was attributed to the (100) diffraction of a hexagonal lattice [26]. A broad diffuse reflection in the region from $2 \theta=20^{\circ}$ to $30^{\circ}$ indicated that the disordered phase was distributed throughout the structure in a non-discrete manner [27]. The reflection at $2 \theta=29.5^{\circ}$ relating to (110) lattice plane conformed to the second-order reflection of peak (100), which indicated that the ordered structure in PAN was affected by the hot-stretching treatment. More detailed information concerning the reflection around $2 \theta=17^{\circ}$ is shown in Fig S3. The pristine PAN samples had a peak at $2 \theta=16.8^{\circ}$. With the rising of heat-treatment temperature, the peaks shifted to a higher degree which proved the conformational change of the molecular segment. The planar zigzag conformation reported by many authors had a smaller inter-planar spacing in the c-axis direction compared with the $3^{1}$ helical conformations [28]. To illustrate this, we calculated the interplanar spacing (d) of different samples by the Bragg Eq. (2)

$$
2 \mathrm{~d} \sin \theta=\mathrm{n} \lambda
$$


where $\theta$ is the diffraction angle and $\lambda$ is the X-ray wavelength [29].

The PAN heat-treated under $200^{\circ} \mathrm{C}$ had a smaller $\mathrm{d}(0.526 \mathrm{~nm})$ than that of the PAN film without heat-treatment $(0.530 \mathrm{~nm})$, which implied the PAN treated by hot-pressing and stretching possessed a larger content of zigzag conformation.

(a)

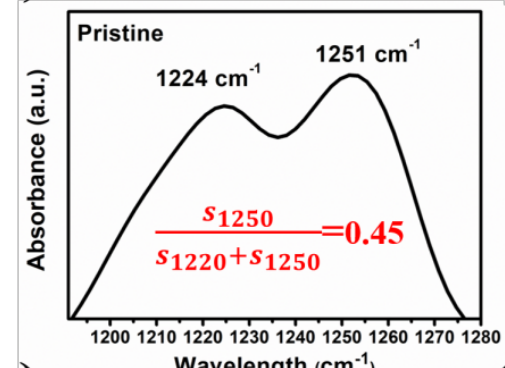

(c)

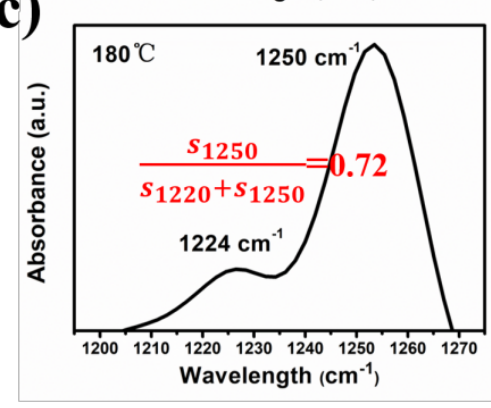

(b)

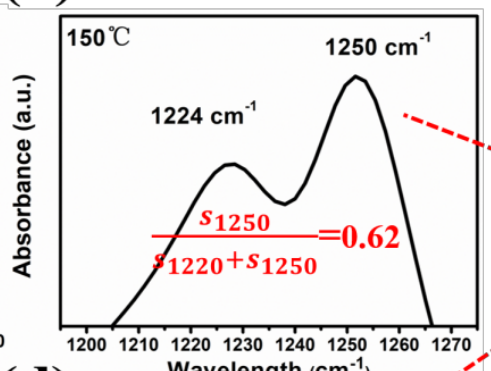

(d)

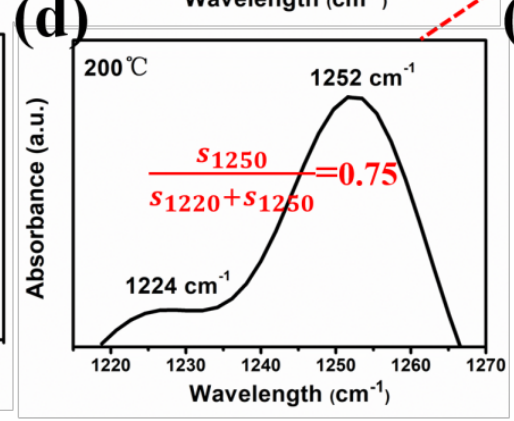

(e)

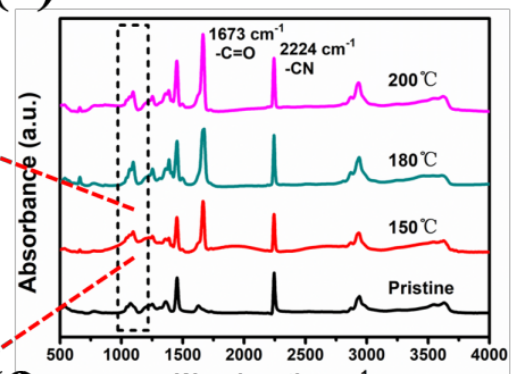

(f)

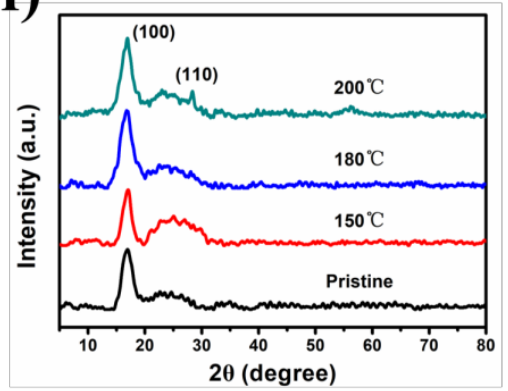

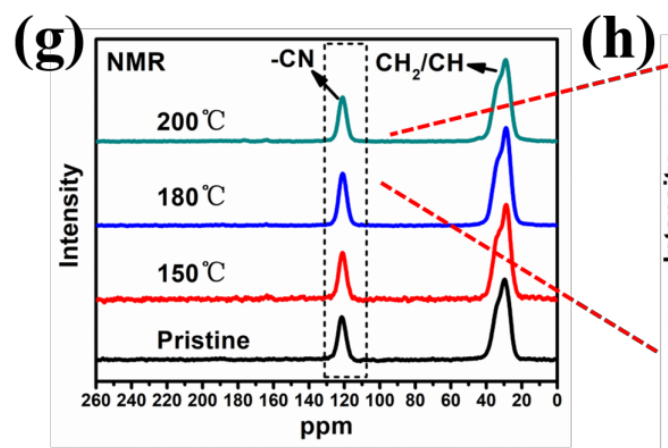

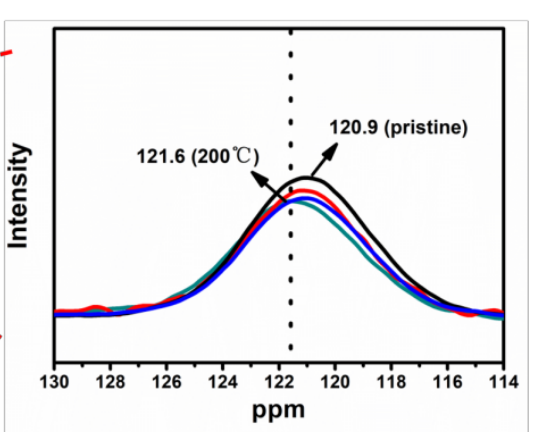

Fig. 2 PAN films after different hot-stretching treatment (roller speed, 1300r $/ \mathrm{min}$ ): amplified FTIR of (a) without treatment (b) $150^{\circ} \mathrm{C}$ (c) $180^{\circ} \mathrm{C}$ (d) $200^{\circ} \mathrm{C}$ (e) FTIR in the full wavenumber range; (f) XRD patterns after heat-treatment under different temperature; (g) solid-state ${ }^{13} \mathrm{C}$ NMR spectra and $(\mathrm{h})$ solid nuclear magnetic resonance peaks of $\mathrm{C}-\mathrm{N}$ triple bond after heat-treatment under different temperature.

The solid nuclear magnetic spectra are another reliable method to characterize the conformational transformation of the PAN. As shown in Fig. 2(g) and (h), the pristine sample had the smallest chemical shift value (120.90 ppm). However, the chemical shift values for the hot-stretched PAN samples were gradually increasing and reached a high value of 121.6 
ppm at $200^{\circ} \mathrm{C}$. This result can be explained by the " $\gamma$-gaussian effect", namely, the C-C bond distance in polymer main chain was slightly affected by molecular conformation [30]. In the zigzag conformation, the $\mathrm{C}-\mathrm{C}$ bond distance in PAN main chain was slightly shorter than that of $3^{1}$ helical conformations, which resulted in electron cloud deflection moving towards the carbon atoms. Therefore, a spatial squeezing effect on the nitrogen atom of the -CN caused the chemical shift of the carbon moving towards the high field [30]. Our experiment results in this paper strongly confirmed that the zigzag conformation was a dominated segment structure in the PAN materials after treated by hot-pressing and stretching procedures.

\subsection{Dielectric properties of PAN film with different molecular structures}

Fig. 3 shows the dielectric properties of PAN films after the hot-pressing and stretching at room temperature. It can be observed from Fig. 3 (a) that the dielectric constant of the pristine PAN film at $1 \mathrm{kHz}$ was 3.1 , which was in excellent agreement with the value reported in the literature [31]. With the rise of the heat treatment temperature, a higher dielectric constant of the samples can be achieved because the heating and stretching process promoted the structural transition of PAN from the non-electroactive ( $3^{1}$ helical conformations) phase to electroactive phase (zigzag conformation). The dielectric constant of all samples presented weak frequency dependence which indicated the dipole polarization originating from - $\mathrm{CN}$ groups made the major contribution to the improvement of dielectric constant. Fig. 3 (b) shows the variation of dielectric loss as a function of the frequency. As was expected, the enhancement of dielectric constant was usually accompanied by the increase of dielectric loss because the large content of polar groups was more sensitive to the applied alternating electric field. In this study, the dielectric loss of the heat-treated PAN only increased from 0.02 
(pristine) to $0.062\left(200^{\circ} \mathrm{C}\right)$ and no loss peak can be observed which implied there was no apparent relaxation behavior in PAN after the conformational transitions [32-33].

(a)

(b)
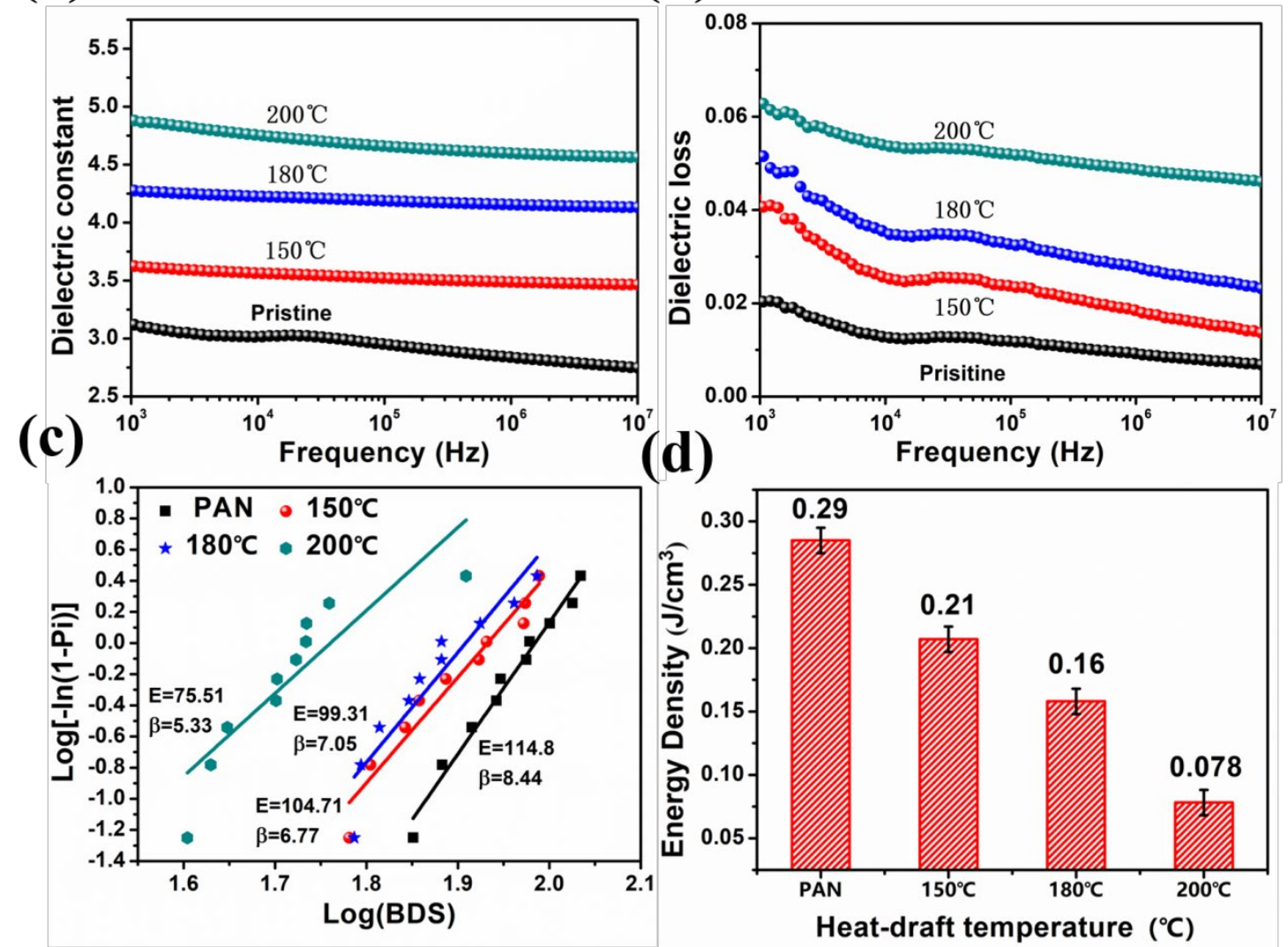

Fig. 3 Room temperature dielectric properties of PAN films after hot-stretching treatment (roller speed 1300r/min): (a) dielectric constant (b) dielectric loss (c) Weibull distribution and deduced characteristic breakdown strength $(\mathrm{kV} / \mathrm{mm})(\mathrm{d})$ energy density

To give further insight into the dielectric properties of the heat-treated PAN films, the characteristic breakdown field strength was analyzed with a two-parameter Weibull distribution function [34]:

$$
\mathrm{P}_{\mathrm{i}}=1-\exp \left[-\left(\mathrm{E}_{\mathrm{i}} / \mathrm{E}_{\mathrm{b}}\right)^{\beta}\right]
$$

where $P_{i}$ is the cumulative probability of electric failure, $E_{i}$ is the measured breakdown strength in the experiment, $E_{b}$ is a scale parameter which refers to the breakdown strength at the cumulative failure probability of $63.2 \%$ and is also regarded as the characteristic breakdown strength, and $\beta$ is the Weibull modulus associated with the linear regressive fit of 
the distribution as followings [35]:

$$
\log \left(-\ln \left(1-P_{i}\right)\right)=\beta\left(\log E_{i}-\log E_{b}\right)
$$

The $\mathrm{P}_{\mathrm{i}}$ values for each $\mathrm{E}$ are assigned based on the $i$ th position of value among the $\mathrm{N}$ ordered E-values from the sample and are calculated by equation (5)

$$
\mathrm{P}_{\mathrm{i}}=(\mathrm{i}-0.3) /(\mathrm{n}+0.4)
$$

where $\mathrm{i}$ is the $i$ th position of value among the $\mathrm{N}$ ordered E-values, $\mathrm{n}$ is the total count of statistical data ( $\mathrm{n}=10$ for this work). The fitted results are shown in Figure $3(\mathrm{c})$. As seen, $\mathrm{E}_{\mathrm{b}}$ decreased substantially with increasing heat treatment temperature, i.e., from $\sim 114.8 \mathrm{kV} / \mathrm{mm}$ for the pristine PAN films to $\sim 75.51 \mathrm{kV} / \mathrm{mm}$ for PAN after $200^{\circ} \mathrm{C}$ treatment. The declined $\mathrm{E}_{\mathrm{b}}$ was attributed to the increase of electroactive phase which was much easier penetrated by the applied voltage and the defects introduced when conducting the electrospinning or heat-treatment procedures. These defects can also be proved by the decrement of Weibull modulus $(\beta)$ because the $\beta$ quantified the scattering of the experimental data and a higher value of $\beta$ represented less scattering, i.e. the decreased $\beta$ indicated that the hot-stretching not only promoted the formation of electro-active phase in the PAN matrix but also introduced some defects caused by the conformational change [36]. Consequently, the energy density under breakdown strength was calculated according to the equation (6)

$$
\mathrm{Ue}=1 / 2 \varepsilon_{\mathrm{r}} \varepsilon_{0} \mathrm{E}_{\mathrm{b}}^{2}
$$

where $\varepsilon_{\mathrm{r}}$ and $\mathrm{E}_{\mathrm{b}}$ are the relative dielectric permittivity and breakdown strength of the materials, respectively. $\varepsilon_{0}$ is the permittivity of vacuum [37]. The result exhibited a decreasing trend of the energy density after heat treatment, which was consistent with the fact that for the polymers possessing relatively low dielectric constant, the energy storage properties were 
usually dominated by the breakdown strength $\left(\mathrm{E}_{\mathrm{b}}\right)$. While the dielectric constant may increase to some extent, the energy storage of the material would drop off tremendously when the $\mathrm{E}_{\mathrm{b}}$ decreased [37]. In our previous research, we had explored the characteristics of the mild heat reduction of GO in the air [38] and combined these work with the research results illustrated above, we chose $180^{\circ} \mathrm{C}$ and $200^{\circ} \mathrm{C}$ as two typical temperatures for the preparation of reduced graphene oxide (rGO)/PAN composite films.

\subsection{The microstructure of GO/PAN nanofibers with core-shell structure}

It has been reported that two-dimensional GO can be folded and curled to form quasi-one-dimensional multilayered structures so that they can be incorporated into the nanofibers [39]. In this work, we demonstrated that coaxial electrospinning was an effective way to prepare core-shell structured nanofibers compared with the traditional electrospinning method because the incorporation of GO may change the properties of the polymer solution such as conductivity and dielectric constant and cause the fiber broken in the electrospinning process [40]. A small addition of GO was enough to make the electrospinning solution broken up and the GO cannot be wrapped by the PAN shell. By implementing the coaxial electrospinning procedures and regulating the concentration of the spinning solution in the core and sheath, a series of core-shell structured GO/PAN composite nanofiber mats were fabricated. Fig. 4 shows the microstructure of single nanofibers. It can be observed from Fig. 4(a) that the pristine PAN fiber exhibited smooth surface and the average diameter of the fibers was $\sim 230 \mathrm{~nm}$. The core-shell structured GO/PAN nanofibers are shown in Fig. 4(b)-(d). With the increment in concentration of PAN solution for sheath, a thicker PAN shell can be 
obtained. Considering a much thicker shell was meaningless for dielectric properties of the composite films, only three typical thicknesses were shown here. The surface of the GO/PAN was not as smooth as the pure PAN fibers which were attributed to the unsteady flow of the PAN solution caused by the incorporation of conductive fillers [41]. To identify the existence of GO in the PAN fibers, TEM-SAED was conducted on the local regions of the fiber surface as presented in the inset of each image. It should be noted that only GO/PAN nanofibers with a shell thickness of $\sim 10 \mathrm{~nm}$ showed a faint diffraction ring because a thicker polymer shell would prohibit the electron injection and the diffraction signal cannot be obtained. the TEM-SAED result was consistent with the research in many works of literature, and the crystal structure of GO was not as perfect as graphene single crystal structures which would show diffraction point [42]. The ATR-FTIR spectrum of nanofiber (shell thickness, 10nm) mats with different GO content was shown in Fig S4. With the increase of GO content, the transmittance band around $1050 \mathrm{~cm}^{-1}$ corresponding to the bending vibration of $-\mathrm{C}-\mathrm{O}$ in the graphene oxide was strengthened [43], which proved the existence of GO in the PAN fibers. 


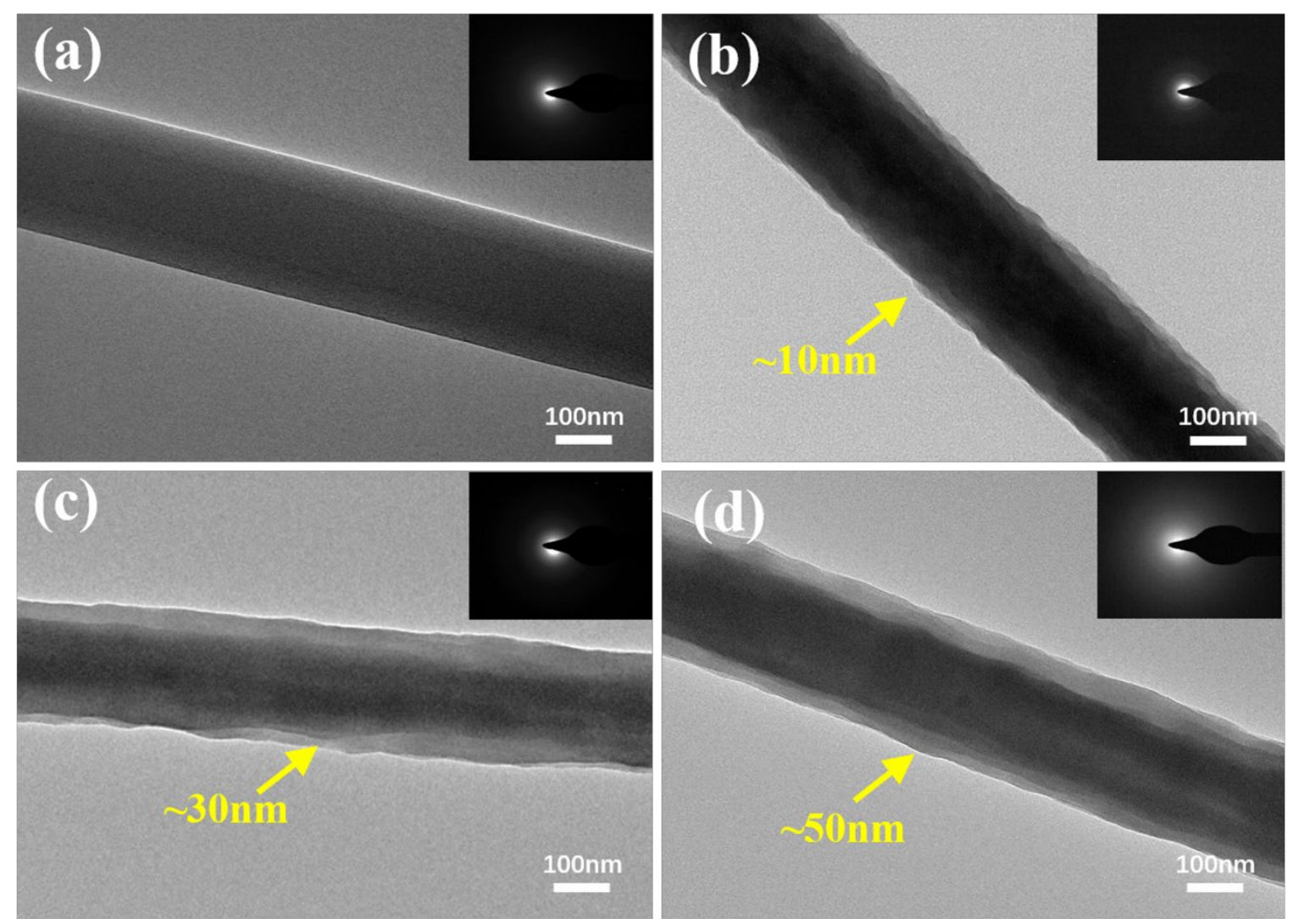

Fig. 4 TEM images of (a) pristine PAN and 20\%-rGO/PAN with different shell thickness: (b) $\sim 10 \mathrm{~nm}$ (c) 30nm (d) $\sim 50 \mathrm{~nm}$

\subsection{The morphology of rGO/PAN composite films based on core-shell structured PAN nanofibers}

The morphology of electrospun nanofiber mats and flexible dense films of PAN and rGO/PAN are shown in Fig. 5. For pristine PAN nanofiber mats collected with a high rotating speed (1300r/min) of drum receiver (Fig. 5a), the nanofibers presented a relatively obvious orientation. This property facilitated the hot-stretching operation in the next step to make the molecular segment generate conformational changes. After hot-pressing, the electrospun nanofiber mats can form dense films which are shown in Fig. 5(b). Despite there were still some defects (circled in yellow in the image) on the surface, the whole film displayed an excellent uniformity as shown in Fig S2. This uniformity endowed the PAN with excellent dielectric properties, otherwise, the dielectric constant would be very low due to the existing 
air in the material.
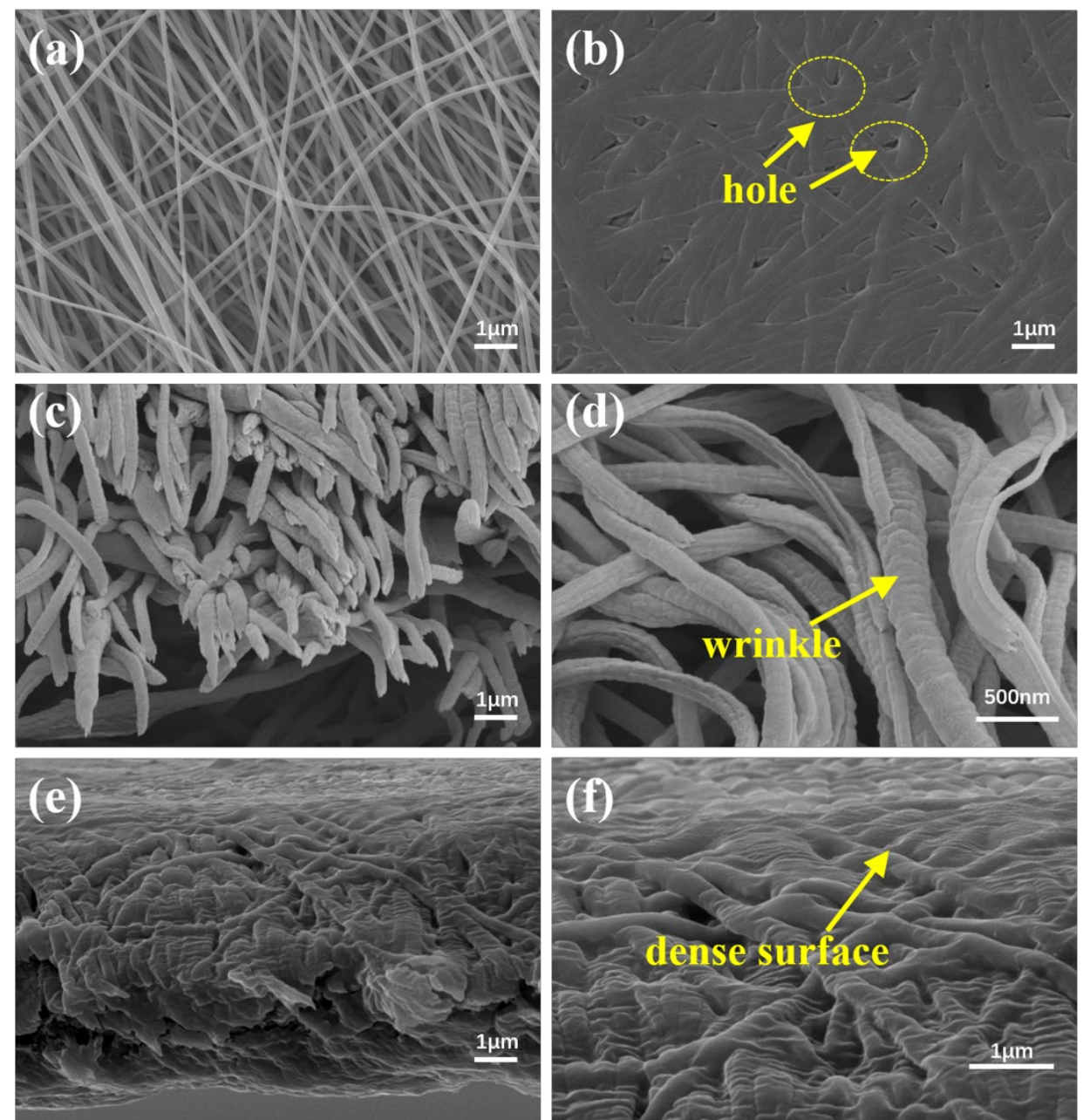

Fig. 5 SEM images of (a) PAN nanofiber mats; (b) hot-pressed PAN composite films; (c) 20\%-rGO/PAN nanofiber mats; (d) magnified 20\%-rGO/PAN nanofiber mats; (e) cross-section of hot-pressed $20 \%$-rGO/PAN composite films; (f) surface of $20 \%$-rGO/PAN composite films

For rGO/PAN nanofiber mats, it can be observed from Fig. 5(c) that each fiber possessed a rough surface and some wrinkles were visible (Fig. 5d) because of the incorporation of graphene oxide. Fig. 5(e) and (f) show the fracture section and top surface of rGO/PAN films after hot-pressed, respectively. The dense films can be obtained that were beneficial for the improvement of dielectric properties. Furthermore, it can be seen from Fig. 5(f) that rGO/PAN composite films possessed a perfect rough micro-nano structure, which also held great promise in the application of nanogenerators [44]. 


\subsection{The dielectric properties of rGO/PAN composite films}

After heat-treatment, the GO was reduced to $\mathrm{rGO}$ so that a typical electrical percolation system was built where rGO was conductive fillers and PAN was polymer matrix. Fig S5. shows the dielectric properties of rGO/PAN composite films prepared by the solution casting method under a heat-treatment temperature of $200^{\circ} \mathrm{C}$. With the increasing of rGO content, a moderate percolation can be observed at $7 \mathrm{wt} \% \mathrm{rGO}$, and the $\mathrm{AC}$ conductivity exceeded $10^{-6}$ $\mathrm{S} / \mathrm{cm}$ at $10^{3} \mathrm{~Hz}$ while the dielectric constant was 60 . When the content of rGO reached $20 \mathrm{wt} \%$ the $\mathrm{AC}$ conductivity hit the maximum value of $10^{-2} \mathrm{~S} / \mathrm{cm}$ which was independent of the variation of frequency within $10^{2}-10^{7} \mathrm{~Hz}$. This phenomenon was attributed to the formation of conductive networks composed of conductive rGO nanofillers which had been reported in many works [45]. The percolative system usually brought about high dielectric loss, therefore, some researchers raised microcapacitor theory to fabricate polymer composites with high dielectric constant and low loss. As is shown in Fig S6. A microcapacitor was composed of two micro-rGO sheet electrodes and a PAN dielectric area in the middle of them (Fig S6. a). In the perpendicular direction of two electrodes, there were numerous micro-capacitors $\left(\mathrm{C}_{\mathrm{i}}\right.$, $\mathrm{C}_{\mathrm{i} 2 \ldots)}$ which can be regarded as series-wound, and a series resistor would be added considering the existence of loss dissipation (Fig S6. b). Ultimately, the overall capacitor can be modeled as a network very similar to a parallel-combination of series-connected resistance (Rs) and capacitance (Cs).

Based on the above model, the capacitance of a microcapacitor was mainly dependent on the thickness of dielectric layers which was described by the Eq. (7)

$$
\mathrm{C}=\mathrm{KS} / \mathrm{L}
$$


where $\mathrm{C}$ is the capacitance of the microcapacitor and $\mathrm{S}$ is the electrode area. $\mathrm{K}$ is a constant, and $\mathrm{L}$ is the thickness of the dielectric layers [38]. The thinner the dielectric layer (L), the greater the capacitance is.

In this study, we prepared a series of rGO/PAN composite films in which rGO was well insulated by PAN dielectric layers with various thicknesses due to the difference of PAN shell thickness in the nanofibers with core-shell structure. Combining the experimental result of Fig S5 and S7, we chose $20 \mathrm{wt} \% \mathrm{rGO}$ as the optimal content to conduct the follow-up research because, for composites containing relatively low content of rGO (e.g.15 wt $\%$ rGO), there was basically no enhancement of dielectric constant with the changing of shell thickness. According to Fig. 6, with the decrease of PAN shell thickness, a higher dielectric constant should be achieved. For the composites with the PAN nanofiber shell thickness of $\sim 70 \mathrm{~nm}$, $\sim 50 \mathrm{~nm}$ and $\sim 30 \mathrm{~nm}$, there was no evident decline of dielectric constant with the rising of test frequency. For the films with a PAN nanofiber shell thickness of $10 \mathrm{~nm}$, however, a slight percolation occurred as the AC conductivity reached $10^{-6} \mathrm{~S} / \mathrm{cm}$ at $10^{3} \mathrm{~Hz}$ and the dielectric loss rose to 0.26 despite the film exhibited the largest dielectric constant of 40 . This phenomenon was attributed to the tunneling effect that the thin dielectrics cannot completely prohibit the travel of charges, which had also been demonstrated by other reports [46]. 
(a)

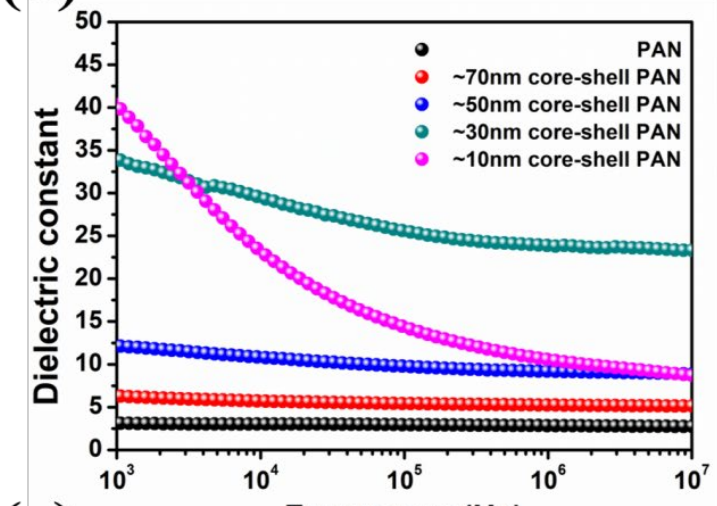

(c)

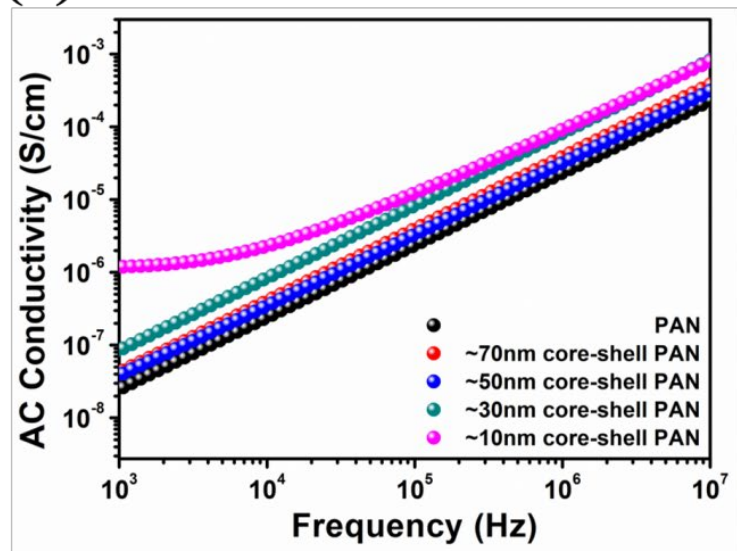

(b)
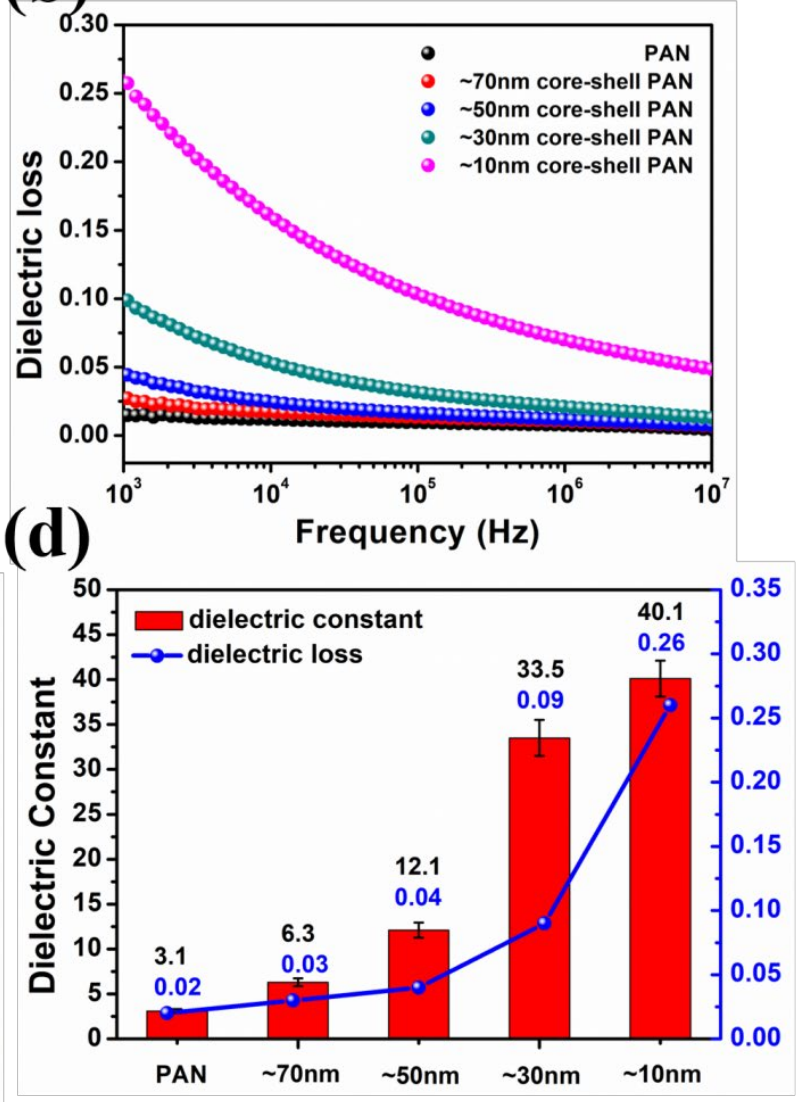

Fig. 6 Room temperature dielectric properties of rGO/PAN composite films with different PAN nanofiber shell thickness after heat treatment under $200^{\circ} \mathrm{C}$ (roller speed $1300 \mathrm{r} / \mathrm{min}$, GO content $20 \mathrm{wt} \%$ ): (a) dielectric constant (b) dielectric loss (c) AC conductivity (d) comparison of dielectric constant and dielectric loss at $1 \mathrm{kHz}$

To broaden the application of this sort of flexible films, we also investigated the high-temperature dielectric properties of the material. Two typical composite films were chosen and tested. One was the films with PAN nanofiber shell thickness of $\sim 30 \mathrm{~nm}$ heat-treated under $200^{\circ} \mathrm{C}\left(200^{\circ} \mathrm{C}-30 \mathrm{~nm}\right.$ shell $\left.\mathrm{rGO} / \mathrm{PAN}\right)$, the other samples were heat-treated under $180^{\circ} \mathrm{C}$ with a PAN nanofiber shell thickness of $\sim 10 \mathrm{~nm}\left(180^{\circ} \mathrm{C}-10 \mathrm{~nm}\right.$ shell $\left.\mathrm{rGO} / \mathrm{PAN}\right)$. Fig. 7 exhibited the distinctions of the two materials. It can be observed from Fig. 7 (a) and (b) that both composite films displayed a very stable dielectric constant over the test frequency range even the temperature was as high as $150^{\circ} \mathrm{C}$. This excellent dielectric property was attributed to the heat-treated procedure before the test in which well-designed zigzag 
electroactive conformations had been formed. The maximum value of dielectric constant for $200^{\circ} \mathrm{C}-30 \mathrm{~nm}$ shell $\mathrm{rGO} / \mathrm{PAN}$ can reach 67 at $150^{\circ} \mathrm{C}$, while for $180^{\circ} \mathrm{C}-10 \mathrm{~nm}$ shell $\mathrm{rGO} / \mathrm{PAN}$ the value was 40. Fig. 7 (c) and (d) depict the variation of the dielectric loss of the two kinds of samples at different temperatures. It can be observed that the $200^{\circ} \mathrm{C}-30 \mathrm{~nm}$ shell $\mathrm{rGO} / \mathrm{PAN}$ possessed a higher dielectric loss $\left(0.85,150^{\circ} \mathrm{C}, 1 \mathrm{kHz}\right)$ compared with the $180^{\circ} \mathrm{C}-10 \mathrm{~nm}$ shell $\mathrm{rGO} / \mathrm{PAN}\left(0.55,150^{\circ} \mathrm{C}, 1 \mathrm{kHz}\right)$ at the same test conditions. This result indicated that $\mathrm{GO}$ after heat-reduction at high temperature had a relatively high conductivity so that the charge migration phenomenon was more evident that caused a relatively high loss. By simultaneously decreasing the heat-treatment temperature and nanofiber shell thickness, the conductivity of the rGO declined but a thinner shell lowered potential energy barrier making the charge migration easier than that of thicker samples.

Fig. 7 (e) and (f) shows the variation of dielectric constant and dielectric loss of $200^{\circ} \mathrm{C}-30 \mathrm{~nm}$ shell $\mathrm{rGO} / \mathrm{PAN}$ and $180^{\circ} \mathrm{C}-10 \mathrm{~nm}$ shell $\mathrm{rGO} / \mathrm{PAN}$ as a function of the temperature at $1 \mathrm{kHz}$. From $30^{\circ} \mathrm{C}$ to $100^{\circ} \mathrm{C}$, the dielectric constant for all samples was steady. When the temperature exceeded $100^{\circ} \mathrm{C}$, a relaxation behavior can be observed for the $200^{\circ} \mathrm{C}-30 \mathrm{~nm}$ shell $\mathrm{rGO} / \mathrm{PAN}$ film, and a slight loss peak appeared around $120^{\circ} \mathrm{C}$ according to Fig. 7 (f). From what was discussed above, it was believed that the dielectric properties of the rGO/PAN films can be tuned by controlling the conductivity of the rGO and shell thickness of the PAN nanofiber through heat-treatment and coaxial electrospinning procedures, respectively. A desirable dielectric property can be achieved for flexible composite films which held great potential in the application of the high-temperature dielectric device. 
(a)

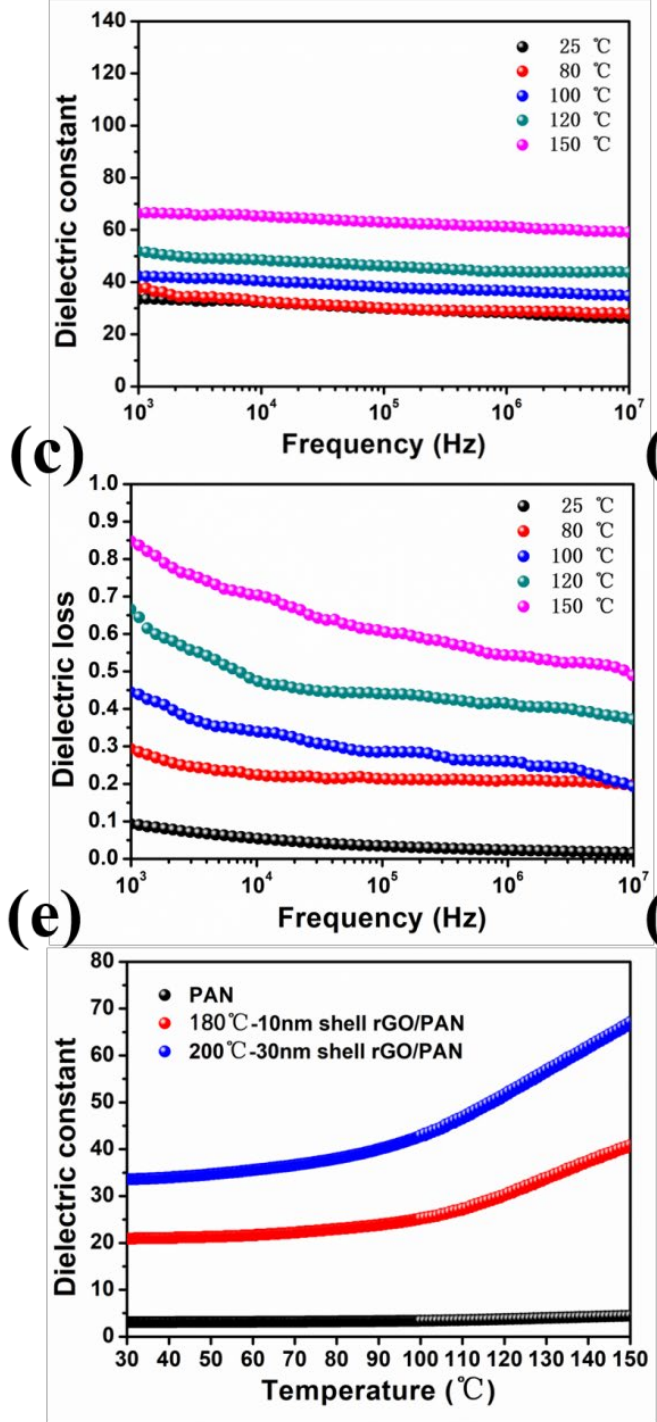

(b)

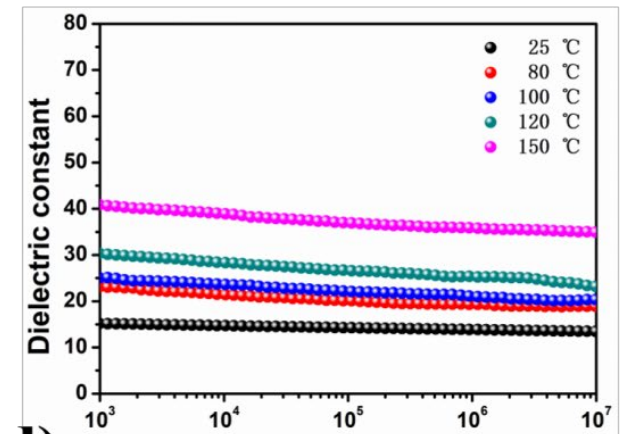

(d)
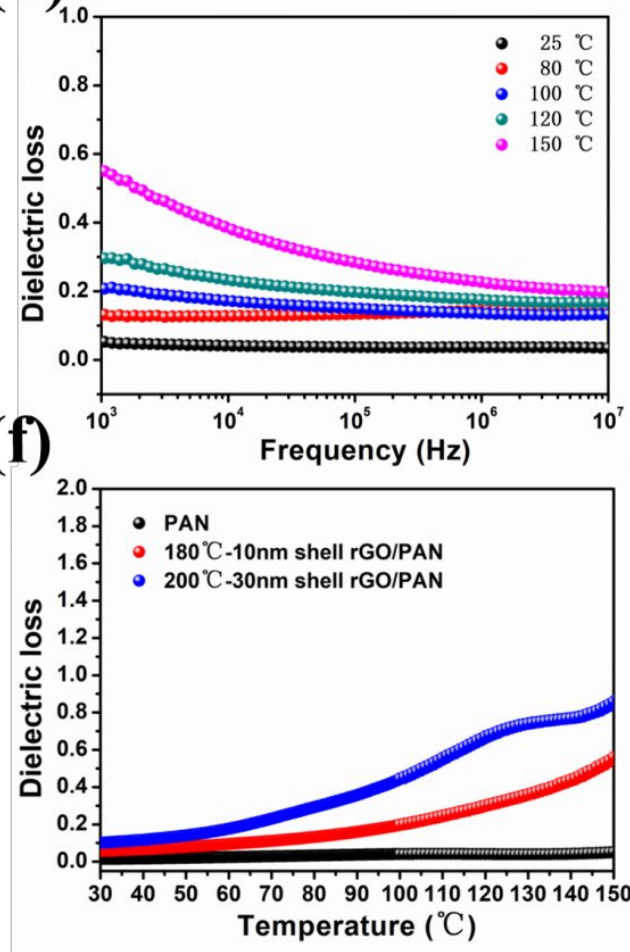

Fig. 7 High-temperature dielectric properties of core-shell structured composite films (roller speed 1300r/min): dielectric constant of (a) $200^{\circ} \mathrm{C}-30 \mathrm{~nm}$ shell rGO/PAN and (b) $180^{\circ} \mathrm{C}-10 \mathrm{~nm}$ shell rGO/PAN; dielectric loss of (c) $200^{\circ} \mathrm{C}-30 \mathrm{~nm}$ shell $\mathrm{rGO} / \mathrm{PAN}$ and (d) $180^{\circ} \mathrm{C}-10 \mathrm{~nm}$ shell $\mathrm{rGO} / \mathrm{PAN}$; (e) dielectric constant and (f) dielectric loss of $200^{\circ} \mathrm{C}-30 \mathrm{~nm}$ shell $\mathrm{rGO} / \mathrm{PAN}$ and $180^{\circ} \mathrm{C}-10 \mathrm{~nm}$ shell $\mathrm{rGO} / \mathrm{PAN}$ as a function of the temperature at $1 \mathrm{kHz}$.

\section{Conclusion}

In this work, we discovered that a flexible rGO/PAN composite films with an excellent dielectric property over a broad temperature range can be prepared by coaxial electrospinning combined with hot-pressing and stretching process. The mechanism behind this result was systematically investigated that the heat treatment process not only reduced the GO into rGO with improved conductivity, forming the microcapacitors in the PAN matrix but also 
promoted the formation of a stable electroactive phase which was beneficial for the enhancement of dielectric constant. Consequently, the $180^{\circ} \mathrm{C}-10 \mathrm{~nm}$ shell $\mathrm{rGO} / \mathrm{PAN}$ composite films presented the most excellent comprehensive dielectric performance with a high dielectric constant $\left(\varepsilon^{\prime}=23,80^{\circ} \mathrm{C} ; \varepsilon^{\prime}=40,150^{\circ} \mathrm{C}\right)$ and low loss $\left(\tan \delta=0.13,80^{\circ} \mathrm{C} ; \tan \delta=0.55\right.$, $150^{\circ} \mathrm{C}$ ) over a broad temperature range, which made it a truly outstanding candidate for the electronics applications in the extreme conditions.

\section{Acknowledgment}

The authors acknowledge the financial support from the National Natural Science Foundation of China (No. U1664251 and No. 51873011).

\section{Reference}

[1] Huan, T. D., Boggs, S., Teyssedre, G., Laurent, C., Cakmak, M., Kumar, S., Ramprasad, R. Advanced polymeric dielectrics for high energy density applications[J]. Progress in Materials Science, 2016, 83(OCT.):236-269.

[2] Huang, X., Sun, B., Zhu, Y., Li, S., Jiang, P. High-k polymer nanocomposites with 1D filler for dielectric and energy storage applications[J]. Progress in Materials Science, 2019, 100: $187-225$.

[3] Tan D Q. Review of Polymer-Based Nanodielectric Exploration and Film Scale-Up for Advanced Capacitors[J]. Advanced Functional Materials, 2019: 1808567.

[4] Tanaka T, Imai T. Advances in nanodielectric materials over the past 50 years[J]. IEEE Electrical Insulation Magazine, 2013, 29(1): 10-23.

[5] Dang, Z. M., Yuan, J. K., Yao, S. H., Liao, R. J. Flexible nanodielectric materials with high permittivity for power energy storage[J]. Advanced Materials, 2013, 25(44): 6334-6365.

[6] Wang, Y., Zhou, X., Chen, Q., Chu, B., Zhang, Q. Recent development of high energy density polymers for dielectric capacitors[J]. IEEE Transactions on Dielectrics and Electrical Insulation, 2010, 17(4): 1036-1042.

[7] Xie, X., Yang, C., Qi, X. D., Yang, J. H., Zhou, Z. W., Wang, Y. Constructing polymeric interlayer with dual effects toward high dielectric constant and low dielectric loss[J]. Chemical Engineering Journal, 2019, 366: 378-389.

[8] Liu, Y., Li, L., Shi, J., Han, R., Wu, P., Yue, X., Li, Q. High dielectric constant composites controlled by a strontium titanate barrier layer on carbon nanotubes towards embedded passive devices[J]. Chemical Engineering Journal, 2019, 373: 642-650.

[9] Wu, S., Li, W., Lin, M., Burlingame, Q., Chen, Q., Payzant, A., Zhang, Q. M. Aromatic polythiourea dielectrics with ultrahigh breakdown field strength, low dielectric loss, and high electric energy density[J]. Advanced Materials, 2013, 25(12): 1734-1738. 
[10] Wang, L., Liu, X., Liu, C., Zhou, X., Liu, C., Cheng, M., Liu, X. Ultralow dielectric constant polyarylene ether nitrile foam with excellent mechanical properties[J]. Chemical Engineering Journal, 2020, 384: 123231.

[11] Li, Q., Chen, L., Gadinski, M. R., Zhang, S., Zhang, G., Li, H. U., Wang, Q. Flexible high-temperature dielectric materials from polymer nanocomposites[J]. Nature, 2015, 523(7562): 576-579.

[12] Zhang, T., Chen, X., Thakur, Y., Lu, B., Zhang, Q., Runt, J., Zhang, Q. M. A highly scalable dielectric metamaterial with superior capacitor performance over a broad temperature[J]. Science Advances, 2020, 6(4): eaax6622.

[13] Bahl, D. P., Mathur, R. B., Dhami, T. L. Modification of polyacrylonitrile fibers to make them suitable for conversion into high-performance carbon fibers [J]. Materials science and engineering, 1985, 73: 105-112.

[14] Dalton S, Heatley F, Budd P M. Thermal stabilization of polyacrylonitrile fibers [J]. Polymer, 1999, 40(20): 5531-5543.

[15] Wang, W., Zheng, Y., Jin, X., Sun, Y., Lu, B., Wang, H., Lin, T. Unexpectedly high piezoelectricity of electrospun polyacrylonitrile nanofiber membranes[J]. Nano Energy, 2019, 56: 588-594.

[16] Yang, X., Guo, Y., Han, Y., Li, Y., Ma, T., Chen, M., Gu, J. Significant improvement of thermal conductivities for BNNS/PVA composite films via electrospinning followed by hot-pressing technology[J]. Composites Part B: Engineering, 2019, 175: 107070.

[17] Gong, L., Nguyen, M. H. T., Oh, E. S. High polar polyacrylonitrile as a potential binder for negative electrodes in lithium-ion batteries[J]. Electrochemistry Communications, 2013, 29: 45-47.

[18] Luo, L., Xu, Y., Zhang, H., Han, X., Dong, H., Xu, X., Lin, J. Comprehensive understanding of high polar polyacrylonitrile as an effective binder for Li-ion battery nano-Si anodes[J]. ACS applied materials \& interfaces, 2016, 8(12): 8154-8161.

[19] Minagawa M, Miyano K, Takahashi M, et al. Minagawa, M., Miyano, K., Takahashi, M., Yoshii, F. [J]. Macromolecules, 1988, 21(8): 2387-2391.

[20] Minagawa, M., Taira, T., Yabuta, Y., Nozaki, K., Yoshii, F. An Anomalous TacticityCrystallinity Relationship: A WAXD Study of Stereoregular Isotactic (83- 25) Poly (Acrylonitrile) Powder Prepared by Urea Clathrate Polymerization[J]. Macromolecules, 2001, 34(11): 3679-3683.

[21] Krimm, S. Infrared spectra of high polymers[M]//Fortschritte der Hochpolymeren-Forschung. Springer, Berlin, Heidelberg, 1960: 51-172.

[22] Bunn, C. W., Holmes, D. R. Chain configurations in crystals of simple linear polymers[J]. Discussions of the Faraday Society, 1958, 25: 95-103.

[23] Henrici-Olive, G., Olivé, S. Molecular interactions and macroscopic properties of polyacrylonitrile and model substances[M]//Chemistry. Springer, Berlin, Heidelberg, 1979: 123-152.

[24] Fu, Z., Gui, Y., Cao, C., Liu, B., Zhou, C., Zhang, H. Structure evolution and mechanism of polyacrylonitrile and related copolymers during the stabilization[J]. Journal of materials science, 2014, 49(7): 2864-2874.

[25] Shimada, I., Takahagi, T., Fukuhara, M., Morita, K., Ishitani, A. FT-IR study of the stabilization reaction of polyacrylonitrile in the production of carbon fibers[J]. Journal of 
Polymer Science Part A: Polymer Chemistry, 1986, 24(8): 1989-1995.

[26] Hobson, R. J., Windle, A. H. Crystalline structure of atactic polyacrylonitrile[J]. Macromolecules, 1993, 26(25): 6903-6907.

[27] Rizzo, P., Auriemma, F., Guerra, G., Petraccone, V., Corradini, P. Conformational disorder in the pseudohexagonal form of atactic polyacrylonitrile[J]. Macromolecules, 1996, 29(27): 8852-8861.

[28] Sawai, D., Yamane, A., Takahashi, H., Kanamoto, T., Ito, M., Porter, R. S. Development of high ductility and tensile properties by a two-stage draw of poly (acrylonitrile): Effect of molecular weight[J]. Journal of Polymer Science Part B: Polymer Physics, 1998, 36(4): 629-640.

[29] Yamane, A., Sawai, D., Kameda, T., Kanamoto, T., Ito, M., Porter, R. S. Development of high ductility and tensile properties upon two-stage draw of ultrahigh molecular weight poly (acrylonitrile)[J]. Macromolecules, 1997, 30(14): 4170-4178.

[30] Bower, D. I., Maddams, W. F. The vibrational spectroscopy of polymers[M]. Cambridge University Press, 1992.

[31] Stupp, S. I., Carr, S. H. Spectroscopic analysis of electrically polarized polyacrylonitrile[J]. Journal of Polymer Science: Polymer Physics Edition, 1978, 16(1): 13-28.

[32] Gupta, A. K., Singhal, R. P., Agarwal, V. K. Effect of heat treatment on dielectric relaxation of polyacrylonitrile: Reversible thermally induced structural change[J]. Journal of Applied Polymer Science, 1981, 26(11): 3599-3608.

[33] Hsu, H. L., Yang, W. C., Lee, Y. L., Yew, T. R. Polyacrylonitrile as a gate dielectric material[J]. Applied physics letters, 2007, 91(2): 023501.

[34] Zhang, X., Shen, Y., Xu, B., Zhang, Q., Gu, L., Jiang, J., Nan, C. W. Giant energy density and improved discharge efficiency of solution-processed polymer nanocomposites for dielectric energy storage[J]. Advanced Materials, 2016, 28(10): 2055-2061.

[35] Xu, X., Liu, W., Li, Y., Wang, Y., Yuan, Q., Chen, J., Wang, H. Flexible mica films for high-temperature energy storage[J]. Journal of Materiomics, 2018, 4(3): 173-178.

[36] Ueda, H., Carr, S. H. Piezoelectricity in polyacrylonitrile[J]. Polymer Journal, 1984, 16(9): 661-667.

[37] Barber, P., Balasubramanian, S., Anguchamy, Y., Gong, S., Wibowo, A., Gao, H., Zur Loye, H. C. Polymer composite and nanocomposite dielectric materials for pulse power energy storage[J]. Materials, 2009, 2(4): 1697-1733.

[38] Su, Y., Zhou, M., Sui, G., Lan, J., Zhang, H., Yang, X. Polyvinyl butyral composites containing halloysite nanotubes/reduced graphene oxide with high dielectric constant and low loss[J]. Chemical Engineering Journal, 2020: 124910.

[39] Cranford, S., Sen, D., \& Buehler, M. J. Meso-origami: folding multilayer graphene sheets[J]. Applied physics letters, 2009, 95(12): 123121.

[40] Wang, L., Shi, X., Zhang, J., Zhang, Y., Junwei, G. Lightweight and robust $\mathrm{rGO} /$ sugarcane derived hybrid carbon foams with outstanding EMI shielding performance[J]. Journal of Materials Science \& Technology, 2020.

[41] Gu, J., Lv, Z., Wu, Y., Guo, Y., Tian, L., Qiu, H., Zhang, Q. Dielectric thermally conductive boron nitride/polyimide composites with outstanding thermal stabilities via in-situ polymerization-electrospinning-hot press method[J]. Composites Part A: Applied Science and 
Manufacturing, 2017, 94: 209-216.

[42] Shalaby, A., Nihtianova, D., Markov, P., Staneva, A. D., Iordanova, R. S., Dimitriev, Y. B. Structural analysis of reduced graphene oxide by transmission electron microscopy[J]. Bulgarian Chemical Communications, 2015, 47(1): 291-295.

[43] Song, P., Qiu, H., Wang, L., Liu, X., Zhang, Y., Zhang, J., Gu, J. Honeycomb structural rGO-MXene/epoxy nanocomposites for superior electromagnetic interference shielding performance[J]. Sustainable Materials and Technologies, 2020: e00153.

[44] Wang, Z. L., Song, J. Piezoelectric nanogenerators based on zinc oxide nanowire arrays[J]. Science, 2006, 312(5771): 242-246.

[45] Last, B. J., Thouless, D. J. Percolation theory and electrical conductivity[J]. Physical review letters, 1971, 27(25): 1719.

[46] Su, Y., Ren, Y., Chen, G. X., Li, Q. Synthesis of high-k and low dielectric loss polymeric composites from crosslinked divinylbenzene coated carbon nanotubes[J]. Polymer, 2016, 100: 179-187.

\section{Supporting Information.}

Additional statistics of PAN structure diagram, photos, XRD spectra, ATR-FTIR spectrum,

Dielectric spectrum, Schematic illustration of the microcapacitors, 


\section{TOC graphic}

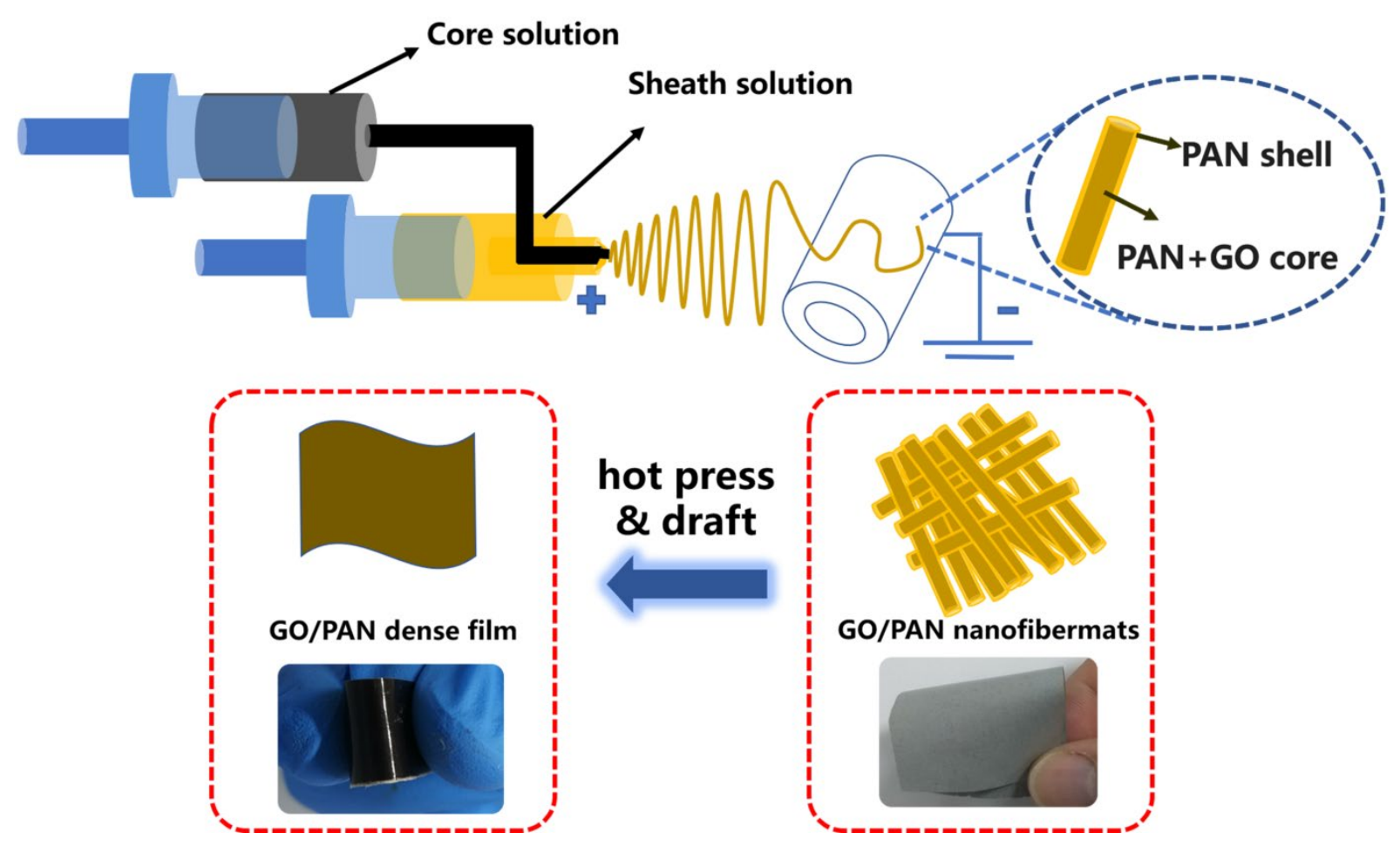

